\title{
Features of the course of pregnancy and child birth in a patient with liver transplantation from a living donor
}

\author{
Gulnar Murzabekova $^{1}$, Karligash Togyzbaeva ${ }^{\mathbf{1}}$, Togzhan Payayeva ${ }^{\mathbf{1}}$, Aigerym Nurmanova ${ }^{1}$, Arlan Rakhatayev ${ }^{1}$ \\ ${ }^{I}$ Corporate fund «University Medical Center» National \\ Research Center for Maternal and Child health, \\ department of obstetrics and gynecology, Astana, \\ Kazakhstan.

\section{ABSTRACT} \\ This paper describes a clinical case of pregnancy and delivery in patients with liver \\ transplantation from a living donor. This case demonstrates the possibility of pregnancy \\ in women who have undergone transplant rejection crisis and successful delivery. Liver \\ transplantation is not anindication for surgical delivery.
}

\section{УДК 616.361:617.053}

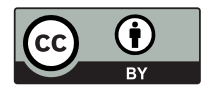

This work is licensed under a

Creative Commons Attribution 4.0

International License

\section{J CLIN MED KAZ 2017; 3(45 SUPPL 3):99-101} Автор для корреспонденции: Мурзабекова Гульнар Саркытказиевна, Корпоративный фонд «University Medical Center» Национальный научный центр материнства и детства, отделение акушерства и гинекологии, ул.Туран 32, Астана, Казахстан.

Телефон номер: +77019999934,

E-mail: gulnara.murzabekova.47@mail.ru
ТІРІ ДОНОРДАН БАУЫР ТРАНСПЛАНТАЦИЯСЫ ЖАСАЛҒАН НАУҚАСТА ЖУКТІЛІК ПЕН БОСАНУ АҒЫМЫНЫН ЕРЕКШЕЛІКТЕРІ Мурзабекова Г.С. ${ }^{1}$, Тогызбаева К.Т. ${ }^{1}$, Паяева Т.К ${ }^{1}$, Нурманова А.М.,

Рахатаев A.M ${ }^{1}$.

${ }^{1}$ Ана мен бала ұлттық ғылыми орталығы «University Medical Center» корпоративтік қоры, акушерлік және гинекология бөлімі, Астана, Қазақстан.

\section{ТҰЖЫРЫМДАМА}

Мақалада тірі донордан бауыр трансплантациясы жасалған науқастың жүктілігі мен босану ағымының клиникалық жағдайы сипатталған. Осы жағдай трасплантантты қабылдамау кризін өткерген әйелдерде жүктілікті және сәтті босану мүмкіндігін куәландырады. Бауыр трансплантациясы оперативті босануға көрсеткіш болып табылмайды.

ОСОБЕННОСТИ ТЕЧЕНИЯ БЕРЕМЕННОСТИ И РОДОВ У ПАЦИЕНТКИ ТРАНСПЛАНТАЦИЕЙ ПЕЧЕНИ ОТ ЖИВОГО ДОНОРА

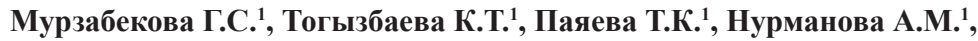

Рахатаев A.M' 1 .

${ }^{1}$ Корпоративный фонд «University Medical Center» Национальный научный центр материнства и детства, отделение акушерства и гинекологии, Астана, Казахстан.

\section{PЕЗЮМЕ}

В статье описывается клинический случай течения беременности и родов у пациентки с трансплантацией печени от живого донора. Данный случай свидетельствует возможности вынашивания беременности у женщин, перенесших криз отторжения трансплантанта и успешного родоразрешения. Пересадка печени не является показанием к проведения оперативного родоразрешения.

\section{Введение}

В последние годы трансплантация печени активно развивается во всем мире. Женщины составляют треть всех реципиентов печени, при этом 75\% из них находятся в репродуктивном возрасте[1]. Планирование беременности возможно после стабилизации состояния в течение года после трансплантации печени, когда риск отторжения трансплантата уменьшается и не зависит от беременности. Появление современных иммуносупрессантов, не обладающих тератогенными свойствами, позволяет вынашивать беременность до жизнеспособности плода. Кормление грудью при приеме таких препаратов противопоказано[2]. Основные риски беременности связаны с развитием таких осложнений как артериальная гипертензия, преэклампсия, почечная дисфункция, ятрогенный диабет, бактериальные и вирусные инфекции, преждевременные роды, синдром задержки развития плода и, конечно, кровотечение в родах и послеродовом периоде. Возможны более частое развитие холестаза во время беременности и дисфункции печени. Все исследователи у пациенток с трансплантированной печенью указывают повышение показателей материнской смертности[3], венозную тромбоэмболию отмечают высокий процент абдоминального родоразрешения. По данным отдела гастроэнтерологии Торонтского университета частота кесарева сечения у пациенток с предшествующей трансплантацией печени выше по сравнению с пациентами в общей популяции[4]. Ведение беременности и родов у пациенток с трансплантированной печенью является мультидисциплинарной проблемой.

В Республике Казахстан с 2011 года реализуется программа по трансплантации печени от живого донора. 


\section{Описание случая}

Ниже мы представляем случай успешного ведения беременности и родоразрешения пациентки с трансплантированной печенью от живого родственного донора.

Беременная C, 27 лет, поступила в АО ННЦМД с диагнозом: беременность 34 недель. Состояние после ортотопической трансплантации правой доли печени от родственного донора от 04.12.2013г. Умеренная анемия. Хронический пиелонефрит, ремиссия.

Из анамнеза:Росла и развивалась соответственновозрасту. Туберкулез, болезнь Боткина,венерические заболевания отрицает. Аутоиммунный гепатит выставлен в 2010 году. Получала глюкокортикостероиды. В 2013 году в ННМЦ (Астана) проведена трансплантация правой доли печени от родственного донора (брата).получала програф, преднизолон, селлсепт по схеме.

Аллергоанамнез не отягощен. Менструальная функция не нарушена. паритет: 1 беременность данная, не запланированная. На учете по беременности с 7-8 недель. В раннем сроке консультирована трансплантологом, даны рекомендации В сроке 14-15 недель получала стационарное лечение в ННМЦ с диагнозом: состояние после ортотопической трансплантации правой доли печени от родственого донора. Криз отторжения трансплантата. Беременность 14-15 недель. Хроническая ЖДА средней степени. Учитывая криз отторжения трансплантанта беременной предложена прерывание беременности, от которого она категорически отказалась. Беременная неоднократно осмотрена гепатологом, трансплантологом. Проводилась коррекция лечения под контролем такролимуса. Доставлена в стационар по линии санавиации с диагнозом: Беременность 39 недель. Состояние после ортотопической трансплантации правой доли печени от родственного донора от 2013г. Умеренная анемия. Хронический пиелонефрит, ремиссия.

Беременная в стационаре полностью обследовалась: данные клинического- лабораторного обследования:

Группа крови O (I) первая, резус - положительный.

ОАК :лейкоциты - 9,20 тыс, Нв - 106 г/л, эритроциты - 3,90 тыс, тромбоциты - 127 тыс, Нт - 30,90\%.

Такролимус: 6,10 нг/мл. ;3,70 нг/мл.

Биохимический анализ крови: общий билирубин - 7,46 мкмоль/л, АЛТ - 7,19 ед/л, АСТ - 13,33 ед/л, ГГТП - 12,12 ед/л, ЩФ - 147,51 ед/л.

Биохимический анализ крови: общий билирубин - 11,92 мкмоль/л, АЛТ - 7,95 ед/л, АСТ - 16,93 ед/л, креатинин - 51,79 мкмоль/л, мочевина - 2,41 ммоль/л, прямой билирубин - 2,39 мкмоль/л, непрямой билирубин 9,53 мкмоль/л, общий белок - 53,20 г/л.

Коагулограмма: МНО - 0,99, АЧТВ - 24,50 с, ТВ 18,20 с, ПВ - 12,0 с, фибриноген - 2,1 г/л.

Оценка состояния плода:

УЗИ органов брюшной полости: Гепатоспленомегаия. Двухсторонний гидрокаликоз. Уплотнение стенок ЧЛС обеих почек. Микронефролитиаз.

УЗИ плода с допплерометрией: По фетомметрии 38 недель +2 дня. Головное предлежание плода. Нарушений МППК не выявлено.

КТГ плода: В пределах нормы. ЭОС.

ЭКГ: Ритм синусовый с ЧС 78 уд/мин. Нормальное доли печени. Хронический пиелонефрит, ремиссия. ХПН0.

Трансплантолог: Состояние после ортотопической трансплантации правой доли печени от родственного донора от 2013г. Беременность 39-40 недель.

Беременной на протяжении всей беременности проводилась иммуносупрессивная терапия прографом 4 мг/сут,метипреда 2 мг в зависимости от концентрации такролимуса в крови.

Такролимус-макролид,получаемыйизстрептомицетов, широко используется после трансплантации печени. При его применении у беременных, по сравнению с циклоспорином, реже развиваются реакция отторжения трансплантата и гестационная гипертензия, но часто диагностируются гестационный диабет и гиперкалиемия, а также нарушение функции почек у новорожденных

В 39 недель беременности, принимая во внимание отсутствие признаков портальной гипертензии на основании данных УЗИ брюшной полости, нормальные показатели лабораторных данных и хорошее состояние трансплантированной печени без нарушений ее функций, стабильное состояние беременной, внутриутробного плода, срок гестации- рекомендованы роды через естественные родовые пути. При присоединении угрожающего состояния плода - кесарево сечение.

В сроке 41 недель, учитывая срок гестации,экстрагенитальную патологию (состояние после ортотопической трансплантации печени)решением консилиума врачей :рекомендовано индукция родов. Беременная была информирована, получено согласие. Учитывая «незрелые» родовые пути, решено произвести индукцию мизопростолом по схеме: по 25 мкг каждые 6 часов в задний свод влагалища под кардиомониторным наблюдением плода, после введения 2-й дозы мизопростола, по данным КТГ диагностировано: угрожающее состояния плода, связи с чем решено родоразрешить путем операции кесарево сечение. Произведена лапаратомия по ДжоелКохену. Кесарево сечение в нижнем маточном сегменте. Родился живой доношенный плод мужского пола, массой 3658 грамм, длиной 54 см с оценкой по шкале Апгар 8-9 баллов, передан неонатологу. Операция прошла без технических осложнении. Объём кровопотери составил500,0 мл. Неонатальный период протекал без осложнений.

В послеродовом периоде проводили исследования контролю гемостаза, определено концентрация такролимуса, бихимических анализов крови.

Проведена антибиотикотерапия в профилактическом режиме цефозалином 2,0гр х 2 раза в сутки, продолжена иммуносупрессияпрографом по 4 мг 2 раза в сутки,метипредом 2 мг в сутки.

Послеродовый период протекал без осложнении, выписана на 5-е сутки с ребенком в удовлетворительном состоянии.

\section{Обсуждение}

Данное клиническое наблюдение, можно, свидетельствует о следующем:

При нормальной функции трансплантированной печени у беременных женщин роды возможно вести консервативно.

Кесарево сечение показано при акушерских осложнениях

Терапевт: Состояние после трансплантации правой 


\section{Выводы}

Успех ведения таких беременных основан на междисциплинарном взаимодействий акушеровгинекологов, трансплантологов и гепатологов.

\section{Литература:}

1. Armenti VT, Radomski JS , Moritz MJ, Gaughan WJ, Hecker WP, Lavelanet A . Report from the National Transplantation Pregnancy Registry (NTPR): outcomes of pregnancy after transplantation. ClinTranspl. 2004; 2(6):103-14.

2. Bonanno C, Dove,L .Pregnancy after liver transplantation. Semin Perinatol. 2007; 31(6):348-53.

3. BurraP, De Bona M. Quality of life following organ transplantation. Liver Transplantation 2010; 16(1):56-63.

4. Cannesson A, Boleslawski E, Declerck N, Mathurin P, Pruvot FR, Dharancy S Daily life, pregnancy, and quality of life after liver transplantation. PresseMed. 2009; 38(9):1319-24.

5. Carla S. Coffin, Abdel Aziz M. Shaheen, Kelly W. Burak, Robert P. Myers. Pregnancy outcomes among liver transplant recipients in the United States: A nationwide case-control analysis. Liver Transplantation 2006; 12(7):1138-1143.

6. Christopher M Estes Response to Surti et al. Pregnancy and liver transplantation. Liver Int. 2009; 29(3): 475.

7. RinellaME . Pregnancy after liver transplantation. Ann Hepatol. 2006; 5(3):212-5.

8. SibandaN , Briggs JD , Davison JM , Johnson RJ , Rudge CJ . Pregnancy after organ transplantation: a report from the UK Transplant pregnancy registry. Transplantation. 2007; 27(83-10):1301-7.

9. SurtiB , Tan J , Saab S . Pregnancy and liver transplantation. LiverInt. 2008; 28(9):1200-6. 